\title{
Performance of bile aspiration plus brushing to diagnose malignant biliary strictures during endo- scopic retrograde cholangiopancreatography
}

Authors

Institutions
Gael S. Roth ${ }^{1,2,3}$, Philippe Bichard ${ }^{1, *}$, Michele Fior-Gozlan ${ }^{4,}$ * , Hubert Roth $^{5,6,7}$, Jean Auroux ${ }^{1}$, Olivier Risse ${ }^{8}$, Christian Letoublon ${ }^{2,3,8}$, Marie Hélène Laverrière ${ }^{4}$, Ivan Bricault ${ }^{3,9}$, Vincent Leroy ${ }^{1,2,3}$, Thomas Decaens $\mathbf{s}^{1,2,3}$

Institutions are listed at the end of article. submitted

11. December 2015 accepted after revision 17. May 2016

\section{Bibliography}

DOI http://dx.doi.org/ 10.1055/s-0042-108854 Published online: 9.8.2016 Endoscopy International Open 2016; 04: E997-E1003 (c) Georg Thieme Verlag KG Stuttgart · New York E-ISSN 2196-9736

\section{Corresponding author}

\section{Thomas Decaens}

Clinique Universitaire d'Hépato-gastroentérologie, Pôle Digidune, CHU Grenoble Alpes

BP 21738043 Cedex 09

Grenoble

France

Fax: +33476765179

tdecaens@chu-grenoble.fr
Background and study aims: Endobiliary brushing during endoscopic retrograde cholangiopancreatography (ERCP) is the main technique used to diagnose a malignant stricture, but has a poor sensitivity.

This study evaluated the diagnostic performance of bile aspiration associated with biliary brushing during ERCP to diagnose a malignant stricture, compared to brushing alone.

Patients and methods: Between January 2007 and December 2012, all consecutive patients undergoing ERCP to treat a biliary stricture were included. After a biliary sphincterotomy, $3 \mathrm{~mL}$ to $10 \mathrm{~mL}$ of bile was aspirated into the brush catheter and collected in a dry sterile tube before and after brushing (to yield three samples). Brushing was performed as commonly recommended.

Results: One hundred eleven patients (68 males, 43 females) were included; mean age $67 \pm 15.4$ years. A final diagnosis of malignant stricture

\section{Introduction}

\section{$\nabla$}

Cholangiocarcinoma is the second commonest primary malignancy of the liver; incidence and mortality rates are increasing worldwide $[1,2]$. At the time of diagnosis, most patients have an unresectable disease and the global 5-year survival rate is $<5 \%$ [3].

Noninvasive techniques, such as magnetic-resonance cholangiopancreatography, have shown great sensitivity and specificity in detecting malignant biliary strictures [4,5] and are particularly efficient at evaluating the resectability of biliary tumors. Nonetheless, MRI does not provide any therapeutic action or anatomopathologic proof. Also, as fewer than $20 \%$ of cholangiocarcinomas are suitable for surgical resection [1], biliary drainage using endoscopic retrograde cholangiopancreatography (ERCP) is often needed in cases

\footnotetext{
* These authors contributed equally.
}

was established in 51 patients, including 43 cholangiocarcinomas; 60 patients had benign strictures. Specificity (Sp) and positive predictive values were $100 \%$ for all samples. The diagnostic performance of the three-sample combination of bile aspiration+brushing+bile aspiration was significantly greater than brushing alone $(P=$ 0.004 ): sensitivity (Se) $=84.3 \%$ vs. $\mathrm{Se}=66.7 \%$. The three-sample combination gave a negative predictive value of $88.2 \%$, and a diagnostic accuracy of $92.8 \%$. When suspicious results were added to malignant results as positive results, the threesample combination gave $\mathrm{Sp}=91.7 \%$ and $\mathrm{Se}=$ $94.1 \%$.

Conclusions: In cases of biliary stricture, conducting bile aspiration before and after brushing significantly increased the ability to diagnose a malignant stricture with a sensitivity of $84.3 \%$ $(P=0.004)$.

of symptomatic biliary stenosis. Thus, ERCP represents a good opportunity to get an anatomopathologic diagnosis in order to guide the therapeutic approach.

Biliary brushing during ERCP was first described by Osnes et al. in 1975 [6] and is nowadays the most commonly used diagnostic technique in cases of symptomatic biliary stricture to provide both a diagnosis as well as being a first-line therapy. It is a safe and simple diagnostic technique $[7,8]$ but its diagnostic performance is considered insufficient, as reported in three recent meta-analyses, with sensitivities between $41 \%$ and $45 \%$ [9-11]. With the aim of increasing diagnostic yield from biliary cytology, many studies have also evaluated new generations of cytobrush, but with disappointing results [12], or in limited series of patients [13].

The aim of our study was to evaluate the diagnostic accuracy of bile aspiration in association with biliary brushing used during ERCP. This three- 
sample combination was compared with brushing alone in a large prospective cohort of patients with a biliary stricture.

\section{Patients and methods}

\section{Patients}

This study was performed at the Universitary Hospital of Grenoble-Alpes, France, from January 1, 2007 to December 31, 2012. Every patient that underwent ERCP to treat a biliary stricture with an undetermined diagnosis was prospectively recruited. Every stenosis was confirmed from preoperative imaging studies.

Patients with a previous diagnosis of bile-duct malignancy were excluded. Stenoses caused by an extrinsic compression identified by preoperative imaging were also excluded. Stenoses with the suspicion of an intraductal tumor were included. If a stenosis was found isolated without any element of etiological orientation on preoperative examinations, it was considered as an undetermined stenosis. In cases of lithiasis extraction, patients were included only if a stenosis was revealed by post-extraction opacification; these stenoses were called post-lithiasis stenoses if no other diagnosis was found.

Groups of patients were defined according to the undetermined character or not of the stenosis, the necessity or not to perform a dilatation before the sampling procedure, and the presence or not of an intraductal prosthesis placed during a previous procedure without realization of the three-sample combination either because first ERCP was performed in another center, or during an emergency. Patients with prosthesis were only included if stenoses were considered as undetermined.

Every patient gave informed written consent. Our study was approved by an institutional review board and respected the principles of the Declaration of Helsinki.

\section{Sampling technique}

After a biliary sphincterotomy, a 0.035-inch guidewire was placed through the stenosis. A single-use cytology brush protected by an 8-Fr catheter (ref. FS-CB-1.5-S Cook ${ }^{\circledR}$ ) was slipped onto the guide wire and positioned above the stricture. Initially, $3 \mathrm{~mL}$ to $10 \mathrm{~mL}$ of bile was aspirated into the brush catheter using a connected syringe and it was collected in a dry sterile tube. Brushing was then conducted using 10 passages in a to-and-fro motion across the stricture. After brushing, a second bile aspiration was conducted according to the same criteria as the first one. Thus, 3 samples were obtained from each patient: 2 aspirates and 1 from brushing. If the stenosis was considered too narrow by the operator, it was dilated using a biliary dilatation balloon between first aspiration and brushing.

\section{Cytopathologic analysis}

Classical cytological analyses (May Grumwald Griemsa, Papanicolaou stainings) were performed on both bile and brushing samples, and thin-layer cytology (ThinPrep ${ }^{\circledR}$ PreservCyt Solution) was done on brushing samples. For each sample, the cytologist determined cellularity according to four categories (insufficient, poor, medium, rich) and the types of cells found (malignant, suspicious; inflammatory; normal).

For each sample, a positive result was defined as the presence of malignant cells and to consider the 3-sample combination as positive, at least 1 sample among 3 had to provide malignant cells. Suspicious, inflammatory and normal samples were considered as negative. In addition, we then analyzed the diagnostic

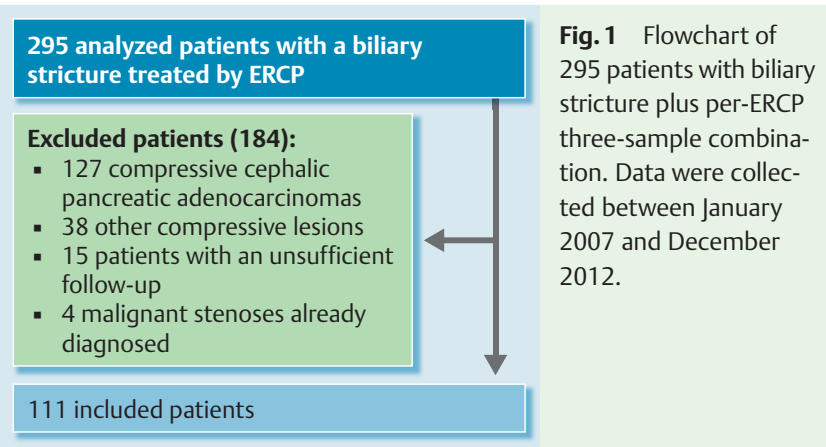

accuracy of each sample when suspicious results were added to malignant results as positive results.

Malignancy was confirmed by histopathologic analysis or using evidence of clinical and radiological progression during the follow-up period. A benign stricture was defined as a stricture without suggestive evolution of a malignancy during a 1-year minimum follow-up, which included clinical, radiological, and biological surveillance, or histopathological analyses.

\section{Statistical analyses}

We used the non-parametric Wilcoxon paired tests to compare the cellularity of the different samples from each patient. The sensitivity/specificity ( $\mathrm{Se} / \mathrm{Sp}$ ) balance, according to the diagnosis obtained from each sampling method, was represented by area under ROC curves (AUC) (with 95\% CI), and paired analyses were used to compare the AUCs between the 3-sample combination and brushing alone (Stata's roccomp command for correlated data), with a Bonferroni correction for multiple tests when required. AUCs were also used to compare the diagnostic performances of each sample between the different groups of patients. When the AUC comparison was not adapted to assess if sensitivity was significantly increased or not because of variations in specificity, both sensitivity and specificity were compared on their respective sides, between different sampling techniques, using the McNemar test.

All statistical tests were 2 -sided, and a $P$ value $<0.05$ was regarded as statistically significant. Statistical analyses were performed using IBM SPSS Statistics software, version 20.0 (IBM Corp., Armonk, NY), and Stata 13 (Stata Corp., College Station, TX).

\section{Results}

$\nabla$

\section{Characteristics of the patients}

From January 1, 2007 to December 31, 2012, 295 patients with a biliary stricture underwent an ERCP. As shown in Fig. 1, 127 patients were excluded because of a compressive pancreatic adenocarcinoma, 38 patients because of other compressive lesions, 15 patients because of a too short follow-up, and 4 patients because a histologic diagnosis had already been obtained before the ERCP. Thus, a total of 111 consecutive patients were included in the analyses.

The patients' main characteristics are summarized in 0 Table 1. There were 68 males and 43 females, with a mean age of $66.8 \pm$ 15.4 years. Biliary stenoses were located in the common bile duct in 77 cases (69.4\%), on the bile-duct bifurcation in 27 cases (24.3\%), and 7 had intrahepatic strictures (6.3\%).

Seventy-six patients (68\%) presented with an undetermined stenosis and 16 of them were later diagnosed as being malignant 
Table 1 Patient characteristics.

\begin{tabular}{|l|l|}
\hline Population characteristics & Data \\
\hline Age, mean (SD) & $66.8(15.4)$ \\
\hline Gender, $n(\%)$ & $68(61 \%)$ \\
\hline Male & $43(39 \%)$ \\
\hline Female & \\
\hline Stenosis localization, $n(\%)$ & $77(69.4 \%)$ \\
\hline Common bile duct & $27(24.3 \%)$ \\
\hline Bile-duct bifurcation & $7(6.3 \%)$ \\
\hline Intra-hepatic ducts & \\
\hline Undetermined stenosis, $n(\%)$ & $76(68 \%)$ \\
\hline Yes & $35(32 \%)$ \\
\hline No & \\
\hline Dilatation before brushing, $n(\%)$ & $24(22 \%)$ \\
\hline Yes & $87(78 \%)$ \\
\hline No & \\
\hline Prosthesis from a previous ERCP, $n(\%)$ & $18(16 \%)$ \\
\hline Yes & $93(84 \%)$ \\
\hline No & $9(8.1 \%)$ \\
\hline Post-ERCP adverse events, $n(\%)$ & $3(2.7 \%)$ \\
\hline Pancreatitis & $3(2.7 \%)$ \\
\hline Angiocholitis & $2(1.8 \%)$ \\
\hline Hemorrhage & $1(0.9 \%)$ \\
\hline Perforation & \\
\hline
\end{tabular}

(22\%). In contrast, 35 (32\%) diagnoses of a tumoral stenosis were already suspected from preoperative imaging because of the presence of an intraductal process or metastasis. Among all the patients, there were 9 ERCPs (8.1\%) with adverse events (AEs) as described in $\bullet$ Table 1.

A final diagnosis of malignant stricture was established in 51 patients with 7 pancreatic adenocarcinomas without any nodules, 43 cholangiocarcinomas and 1 ampulloma, and in 60 cases, the stenosis was considered benign as detailed in Table 2. Sixteen malignant stenoses and 10 benign stenoses were confirmed by histologic examination.

\section{Cytology yield}

All included ERCPs allowed all 3 samples to be obtained. As shown in Fig. 2, only 17 (15.3\%) brushing samples were rich in cells whereas bile aspiration produced samples with rich cellularity in 62 (55.9\%) cases before brushing and 66 (59.5\%) cases after brushing. The addition of medium-cellularity samples to the cell-rich samples, considered as "high-quality" samples, represented $74.8 \%$ and $80.2 \%$ of samples with bile aspiration before and after brushing, respectively, whereas brushing provided only $52.3 \%$ of "high quality" samples. Consequently, bile aspiration provided better-quality samples than brushing alone $(P<0.0001)$, without significant difference between both bile aspiration samples $(P=0.484)$.

\section{Diagnostic performances}

The data on the diagnosis of malignant stenoses and the detection of malignant cells through cytology are shown in $\bullet$ Table 3 . Each sampling technique had a specificity (Sp) and a positive predictive value (PPV) of $100 \%$. The sensitivities (Se) and negative predictive values (NPVs) were as follows: $66.7 \%$ and $77.9 \%$ for brushing alone, $72.6 \%$ and $81.1 \%$ when bile aspiration was done before brushing, and $76.5 \%$ and $83.3 \%$ when bile aspiration was done after brushing. None of these results varied significantly from each other.

\begin{tabular}{|l|l|}
\hline Table 2 Final diagnosis. \\
\hline Type of stenosis & $\mathbf{n}(\%)$ \\
\hline Malignant strictures & $51(46 \%)$ \\
\hline Pancreatic adenocarcinoma & $7(6 \%)$ \\
\hline Cholangiocarcinoma & $43(39 \%)$ \\
\hline Peri-hilar tumor & 24 \\
\hline Common bile duct & 18 \\
\hline Intrahepatic & 1 \\
\hline Ampullary carcinoma & 1 \\
\hline Benign strictures & $\mathbf{6 0}(\mathbf{5 4} \%)$ \\
\hline Pancreatitis & $16(14 \%)$ \\
\hline Acute pancreatitis & 3 \\
\hline Chronic pancreatitis & 13 \\
\hline Primary sclerosing cholangitis & 10 \\
\hline Postoperative stenosis & 10 \\
\hline Post-lithiasis stenosis & 8 \\
\hline Odditis and other benign ampullary stenoses & 7 \\
\hline Undetermined benign stenosis & 9 \\
\hline
\end{tabular}

Se and NPV of the 3-sample combination reached respectively $84.3 \%$ and $88.2 \%$, with a diagnostic accuracy of $92.8 \%$ which was significantly superior to brushing alone $(P=0.004)$.

Combining brushing with only 1 bile-aspiration sample as a way to eventually increase the cost-effectiveness of the technique still gave significantly higher results than brushing alone, as shown in - Table 3, with the same ability to diagnose a malignant stenosis as the 3-sample combination, for the association of brushing plus bile aspiration after brushing.

When suspicious cells in addition to malignant cells were considered as positive results ( Table 4), brushing alone was able to diagnose malignant stenoses at $\mathrm{Sp}=95 \%$ and $\mathrm{Se}=80.4 \%$, whereas the 3-sample combination had significantly greater sensitivity (Se=94.1\%, McNemar test: $P=0.008$ ), without a significant decrease in specificity ( $\mathrm{Sp}=91.7 \%$, McNemar test: $P=0.157)$.

\section{Group analyses}

Data for undetermined stenosis $(n=76)$ are summarized in - Table5. Sp and PPV were still $100 \%$, and Se and NPV were as follows: brushing alone, $43.8 \%$ and $87.0 \%$, respectively, and 3-sample combination, $62.5 \%$ and $90.9 \%$, respectively. No statistical differences were found $(P=0.06)$. When suspicious cytologic results were combined with malignant cells, brushing alone resulted in Sp of $95.0 \%$ and Se of $68.8 \%$ whereas the 3sample combination resulted in Sp of $91.7 \%$ and Se of $87.5 \%$ ( Table 6). No statistical differences were found (AUCs comparison: $P=0.136$; McNemar test: $P=0.0833$ ).

In patients with a biliary dilatation before sampling $(n=24)$, diagnostic accuracy was unchanged for brushing, and increased for the 3-sample combination with sensitivity of $100 \%(P=0.002)$ (ه Table 7).

In patients with a prosthesis from a previous procedure $(n=18)$, diagnostic accuracy was dramatically decreased with a sensitivity of only $40 \%$ for both brushing alone and the 3-sample combination ( Table 8).

\section{Discussion}

$\nabla$

This study shows that the combination of bile aspiration and brushing increased diagnostic yield and gave richer cellularity, and thus, greater diagnostic accuracy from cytologic analyses 


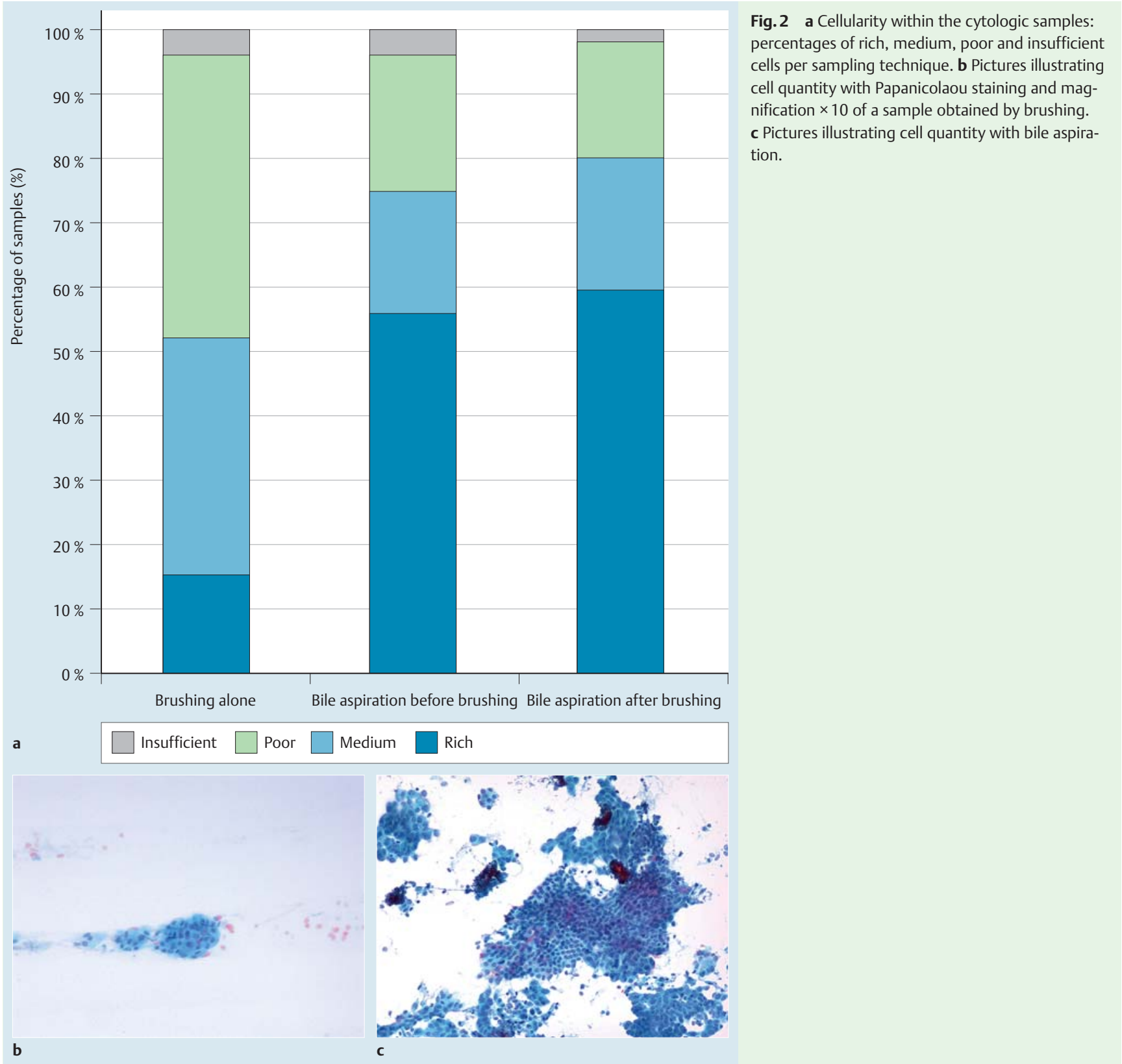

Table 3 Accuracy of diagnosis of malignancy after detection of malignant cells according to the different sampling methods.

\begin{tabular}{|c|c|c|c|c|c|c|c|}
\hline Detection of malignant cells & $\begin{array}{l}\text { Sp } \\
(\%)\end{array}$ & $\begin{array}{l}\text { Se } \\
\text { (\%) }\end{array}$ & $\begin{array}{l}\text { PPV } \\
\text { (\%) }\end{array}$ & $\begin{array}{l}\text { NPV } \\
\text { (\%) }\end{array}$ & $\begin{array}{l}\text { Diagnostic } \\
\text { accuracy (\%) }\end{array}$ & $\begin{array}{l}\text { AUC } \\
{[95 \% \mathrm{Cl}]}\end{array}$ & $\begin{array}{l}\text { Bonferroni } \\
P \text { value }\end{array}$ \\
\hline Brushing alone & 100 & 66.7 & 100 & 77.9 & 84.7 & $\begin{array}{l}0.833 \\
{[0.768: 0.899]}\end{array}$ & Reference \\
\hline Bile aspiration before brushing & 100 & 72.6 & 100 & 81.1 & 87.4 & $\begin{array}{l}0.863 \\
{[0.786: 0.940]}\end{array}$ & 1 \\
\hline Bile aspiration after brushing & 100 & 76.5 & 100 & 83.3 & 89.2 & $\begin{array}{l}0.882 \\
{[0.824: 0.941]}\end{array}$ & 0.646 \\
\hline Three-sample combination & 100 & 84.3 & 100 & 88.2 & 92.8 & $\begin{array}{l}0.922 \\
{[0.871: 0.972]}\end{array}$ & 0.004 \\
\hline \multicolumn{8}{|l|}{ Combinations of two samples } \\
\hline Bile aspiration and then brushing & 100 & 78.4 & 100 & 84.5 & 89.2 & $\begin{array}{l}0.892 \\
{[0.823: 0.922]}\end{array}$ & 0.039 \\
\hline Brushing and then bile aspiration & 100 & 84.3 & 100 & 88.2 & 92.8 & $\begin{array}{l}0.922 \\
{[0.871: 0.972]}\end{array}$ & 0.004 \\
\hline
\end{tabular}

Sp, specificity; Se, sensitivity; PPV, positive predictive value; NPV, negative predictive value. 
Table 4 Accuracy of diagnosis of malignancy after detection of malignant and suspicious cells with different sampling methods.

\begin{tabular}{|c|c|c|c|c|c|c|c|}
\hline Detection of malignant and suspicious cells & $\begin{array}{l}\text { Sp } \\
\text { (\%) }\end{array}$ & $\begin{array}{l}\text { Se } \\
\text { (\%) }\end{array}$ & $\begin{array}{l}\text { PPV } \\
\text { (\%) }\end{array}$ & $\begin{array}{l}\text { NPV } \\
\text { (\%) }\end{array}$ & $\begin{array}{l}\text { Diagnostic } \\
\text { accuracy (\%) }\end{array}$ & $\begin{array}{l}\text { AUC } \\
{[95 \% \mathrm{Cl}]^{1}}\end{array}$ & $P$ value \\
\hline Brushing alone & 95.0 & 80.4 & 93.2 & 85.1 & 88.3 & $\begin{array}{l}0.877 \\
{[0.804: 0.950]}\end{array}$ & Reference \\
\hline Bile aspiration before brushing & 95.0 & 84.3 & 93.5 & 87.7 & 90.0 & $\begin{array}{l}0.897 \\
{[0.829: 0.964]}\end{array}$ & ND \\
\hline Bile aspiration after brushing & 93.3 & 86.3 & 91.7 & 88.9 & 90.2 & $\begin{array}{l}0.898 \\
{[0.832: 0.964]}\end{array}$ & ND \\
\hline Three-sample combination & 91.7 & 94.1 & 90.6 & 94.8 & 92.8 & $\begin{array}{l}0.945 \\
{[0.895: 0.994]}\end{array}$ & 0.054 \\
\hline
\end{tabular}

Sp, specificity; Se, sensitivity; PPV, positive predictive value; NPV, negative predictive value; AUC, area under the curve.

$N D=$ not determined because of irrelevance of this statistical comparison and the increase of alpha error if done.

${ }^{1}$ AUCs were compared between "Brushing alone" and the "Three combined samples".

Table 5 Accuracy of diagnosis of malignancy after detection of malignant cells with different sampling methods for undetermined stenoses.

\begin{tabular}{|c|c|c|c|c|c|c|c|}
\hline Detection of malignant cells & $\begin{array}{l}\text { Sp } \\
\text { (\%) }\end{array}$ & $\begin{array}{l}\text { Se } \\
\text { (\%) }\end{array}$ & $\begin{array}{l}\text { PPV } \\
\text { (\%) }\end{array}$ & $\begin{array}{l}\text { NPV } \\
\text { (\%) }\end{array}$ & $\begin{array}{l}\text { Diagnostic } \\
\text { accuracy (\%) }\end{array}$ & $\begin{array}{l}\text { AUC } \\
{[95 \% \mathrm{Cl}]^{1}}\end{array}$ & $P$ value \\
\hline Brushing & 100 & 43.8 & 100 & 87.0 & 88.2 & $\begin{array}{l}0.719 \\
{[0.593: 0.844]}\end{array}$ & Reference \\
\hline Bile aspiration before brushing & 100 & 43.8 & 100 & 87.0 & 88.2 & & ND \\
\hline Bile aspiration after brushing & 100 & 50.0 & 100 & 88.2 & 89.5 & & ND \\
\hline Three-sample combination & 100 & 62.5 & 100 & 90.9 & 92.1 & $\begin{array}{l}0.813 \\
{[0.690: 0.935]}\end{array}$ & 0.063 \\
\hline
\end{tabular}

Sp, specificity; Se, sensitivity; PPV, positive predictive value; NPV, negative predictive value; AUC, area under the curve.

$\mathrm{ND}=$ not determined because of irrelevance of this statistical comparison and the increase of alpha error if done.

${ }^{1}$ AUCs were compared between „Brushing alone” and the "Three combined samples”.

Table 6 Accuracy of diagnosis of malignancy after detection of malignant and suspicious cells with different sampling methods for undetermined stenoses.

\begin{tabular}{|c|c|c|c|c|c|c|c|}
\hline Detection of suspicious and malignant cells & $\begin{array}{l}\text { Sp } \\
(\%)\end{array}$ & $\begin{array}{l}\text { Se } \\
\text { (\%) }\end{array}$ & $\begin{array}{l}\text { PPV } \\
\text { (\%) }\end{array}$ & $\begin{array}{l}\text { NPV } \\
\text { (\%) }\end{array}$ & $\begin{array}{l}\text { Diagnostic } \\
\text { accuracy (\%) }\end{array}$ & $\begin{array}{l}\text { AUC } \\
{[95 \% \mathrm{Cl}]^{1}}\end{array}$ & $P$ value \\
\hline Brushing & 95.0 & 68.8 & 78.6 & 91.9 & 89.5 & $\begin{array}{l}0.819 \\
{[0.698: 0.939]}\end{array}$ & Reference \\
\hline Bile aspiration before brushing & 95.0 & 68.8 & 78.6 & 91.9 & 89.5 & & ND \\
\hline Bile aspiration after brushing & 93.3 & 68.8 & 73.3 & 91.8 & 88.2 & & ND \\
\hline Three-sample combination & 91.7 & 87.5 & 73.7 & 96.5 & 90.8 & $\begin{array}{l}0.896 \\
{[0.805: 0.987]}\end{array}$ & 0.136 \\
\hline
\end{tabular}

Sp, specificity; Se, sensitivity; PPV, positive predictive value; NPV, negative predictive value; AUC, area under the curve.

$\mathrm{ND}=$ not determined because of irrelevance of this statistical comparison and the increase of alpha error if done.

Table 7 Detection of malignant cells with or without dilatation before brushing.

\begin{tabular}{|c|c|c|c|c|c|c|c|}
\hline Detection of malignant cells & $\begin{array}{l}\text { Dilatation } \\
\text { (Yes/No) }\end{array}$ & $\begin{array}{l}\text { Sp } \\
(\%)\end{array}$ & $\begin{array}{l}\text { Se } \\
\text { (\%) }\end{array}$ & $\begin{array}{l}\text { PPV } \\
\text { (\%) }\end{array}$ & $\begin{array}{l}\text { NPV } \\
\text { (\%) }\end{array}$ & $\begin{array}{l}\text { AUC } \\
{[95 \% \mathrm{Cl}]}\end{array}$ & $P$ value \\
\hline \multirow[t]{2}{*}{ Brushing } & No & 100 & 66.7 & 100 & 75.0 & $\begin{array}{l}0.833 \\
{[0.758: 0.908]}\end{array}$ & Reference \\
\hline & Yes & 100 & 66.7 & 100 & 78.7 & $\begin{array}{l}0.833 \\
{[0.694: 0.973]}\end{array}$ & 1.000 \\
\hline \multirow[t]{2}{*}{ Bile aspiration before brushing } & No & 100 & 66.7 & 100 & 78.7 & $\begin{array}{l}0.833 \\
{[0.758: 0.908]}\end{array}$ & Reference \\
\hline & Yes & 100 & 91.7 & 100 & 92.3 & $\begin{array}{l}0.958 \\
{[0.877: 1.000]}\end{array}$ & 0.027 \\
\hline \multirow[t]{2}{*}{ Bile aspiration after brushing } & No & 100 & 71.8 & 100 & 81.4 & $\begin{array}{l}0.859 \\
{[0.787: 0.931]}\end{array}$ & Reference \\
\hline & Yes & 100 & 91.7 & 100 & 92.3 & $\begin{array}{l}0.958 \\
{[0.877: 1.000]}\end{array}$ & 0.073 \\
\hline \multirow[t]{2}{*}{ Three-sample combination } & No & 100 & 83.7 & 100 & 85.7 & $\begin{array}{l}0.897 \\
{[0.833: 0.962]}\end{array}$ & Reference \\
\hline & Yes & 100 & 100 & 100 & 100 & $\begin{array}{l}1.000 \\
{[1.000: 1.000]}\end{array}$ & 0.002 \\
\hline
\end{tabular}

Sp, specificity; Se, sensitivity; PPV, positive predictive value; NPV, negative predictive value; AUC, area under the curve. 
Table 8 Detection of malignant cells with or without a prosthesis before ERCP.

\begin{tabular}{|c|c|c|c|c|c|c|c|}
\hline Detection of malignant cells & $\begin{array}{l}\text { Prosthesis } \\
\text { (Yes/No) }\end{array}$ & $\begin{array}{l}\text { Sp } \\
(\%)\end{array}$ & $\begin{array}{l}\text { Se } \\
\text { (\%) }\end{array}$ & $\begin{array}{l}\text { PPV } \\
\text { (\%) }\end{array}$ & $\begin{array}{l}\text { NPV } \\
\text { (\%) }\end{array}$ & $\begin{array}{l}\text { AUC } \\
{[95 \% \mathrm{Cl}]}\end{array}$ & $P$ value \\
\hline \multirow[t]{2}{*}{ Brushing } & No & 100 & 69.6 & 100 & 77.0 & $\begin{array}{l}0.847 \\
{[0.781: 0.915]}\end{array}$ & Reference \\
\hline & Yes & 100 & 40.0 & 100 & 81.2 & $\begin{array}{l}0.700 \\
{[0.460: 0.940]}\end{array}$ & 0.245 \\
\hline \multirow[t]{2}{*}{ Bile aspiration before brushing } & No & 100 & 78.7 & 100 & 82.5 & $\begin{array}{l}0.891 \\
{[0.831: 0.952]}\end{array}$ & Reference \\
\hline & Yes & 100 & 20.0 & 100 & 76.5 & $\begin{array}{l}0.600 \\
{[0.404: 0.796]}\end{array}$ & 0.005 \\
\hline \multirow[t]{2}{*}{ Bile aspiration after brushing } & No & 100 & 80.4 & 100 & 83.9 & $\begin{array}{l}0.902 \\
{[0.844: 0.960]}\end{array}$ & Reference \\
\hline & Yes & 100 & 40.0 & 100 & 81.2 & $\begin{array}{l}0.700 \\
{[0.460: 0.940]}\end{array}$ & 0.109 \\
\hline \multirow[t]{2}{*}{ Three-sample combination } & No & 100 & 89.1 & 100 & 90.4 & $\begin{array}{l}0.945 \\
{[0.900: 0.991]}\end{array}$ & Reference \\
\hline & Yes & 100 & 40.0 & 100 & 81.2 & $\begin{array}{l}0.700 \\
{[0.460: 0.940]}\end{array}$ & 0.049 \\
\hline
\end{tabular}

Sp, specificity; Se, sensitivity; PPV, positive predictive value; NPV, negative predictive value; AUC, area under the curve.

compared to brushing alone. Indeed, by providing a large amount of cells, bile aspiration increases the probability of detecting tumor cells. Brushing has a low yield and is often insufficient to establish a clear diagnosis, but none of the bile samples alone had statistically greater diagnostic accuracy than brushing. Thus, there is no argument for excluding brushing from the standard procedure, and it has to be associated with at least 1 bile sample, especially bile-aspiration after brushing whose association reaches the same rate of diagnosis to detect malignant cells as the 3 -sample combination ( $\mathrm{Se}=84.3 \%, \mathrm{Sp}=100 \%$ ). Brushing may potentiate the cytologic yield from bile aspiration conducted after brushing by increasing desquamation of bile-duct cells through its mechanical action, even if we did not find statistical difference between bile aspiration before and after brushing. Also, good performance of brushing alone could be due, in part, to an increase in cells trapped in the brush during first bile aspiration.

In this study, we first tested malignant cells only, to obtain a positive-diagnosis result, and excluded suspicious results from the analyses. However, we then tested the diagnostic performances of each of the 3 different samples individually and in combination when suspicious results were included in the positive results. The 3-sample combination showed very high sensitivity ( $\mathrm{Se}=94.1 \%$ ), which was statistically superior to brushing alone $(P=0.008)$ and did not significantly decrease specificity $(\mathrm{Sp}=$ $91.7 \%$ ). This confirms the results of a previous study, conducted in 2012, which assessed bile aspiration in 42 patients with a suspected malignant biliary stricture and found a sensitivity of $89 \%$ to detect malignant stenosis when combining suspicious and malignant cells [14].

ERCP is often done after determinant imaging, such as computed tomography scans or magnetic resonance imaging. Consequently, in our study, the majority of malignant biliary stenoses were already suspected after the preoperative work-up. Nevertheless, we wanted to analyze the diagnostic performance of our technique in cases of biliary stenoses when imaging could not provide a suspected diagnosis, which corresponds to a classical but difficult situation for clinicians. In these undetermined stenoses, a diagnosis of malignancy within each sample remained low, without a significant difference between brushing alone and the 3 -sample combination, $\mathrm{Se}=43.8 \%$ vs. $62.5 \%$ (=0.063), probably because of a lack of statistical power. The addition of suspicious results to positive results revealed a sensitivity to diagnose malignant stenoses of almost $90 \%$ in undetermined stenoses when the 3 samples were combined, with only 2 false-negative results (one ampullary adenocarcinoma diagnosed 1 year later, and 1 cholangiocarcinoma), whereas the sensitivity of brushing alone remained inferior to $70 \%(P=0.083)$. Even if this did not reach statistical difference, it showed again how much bile aspiration seems to help the detection of malignant stenoses. The addition of suspicious cells could increase the risk of unnecessary surgical procedure. However, as mentioned before, realization of ERCP is always included in a clinical context with additional examinations which can guide the strategy. Moreover, avoid a false-negative result is also a major issue regarding the severity of biliary malignant diseases. Thus, the treatment of patients with suspicious cells without malignant cells has to be discussed and requires a multidisciplinary decision.

As the presence of an endobiliary prosthesis dramatically decreased the sensitivity of all samples, it seems essential to assess the 3-sample combination before any prosthesis placement to increase the chance of achieving a cytologic diagnosis. In addition, our new method had an overall $\mathrm{AE}$ rate that was comparable to large series in the literature $[7,8,15]$.

One of the limits of our study is its monocentric nature. Indeed cytologic diagnosis has interobserver variation [16]. Because the vast majority of the samples were analyzed by the same pathologist, the result of this monocentric study has to be confirmed by a multicenter prospective study comparing the brushing alone to the 3-sample combination. A bigger study would also increase the statistical power, which is limited especially for undetermined stenosis. Another limit is the absence of blind cytologic analysis. Nevertheless, in all undetermined stenoses, cytologists were, by definition, blinded, and diagnostic performances of bile aspiration were still much better than those of the brushing. In our study, only a few patients had a histopathologic confirmation for obvious ethical reasons. In the large majority of patients, the diagnostic confirmation was based on their clinical course in order to confirm or exclude the possibility of a malignant stenosis, as described in the method section. This attitude corresponds to the present standards of clinical practice in front of a biliary stenosis. 
By its greater sensitivity to diagnose malignant biliary stenosis, it should reduce the number of unnecessary additional diagnostic procedures and the overall cost of diagnosing biliary strictures, even though cost-effectiveness was not investigated. Moreover, this technique can be used by all biliary endoscopists who perform ERCP, as its technical difficulty is the same as for brushing alone. Our method seemed to have a much higher diagnostic yield than another simple and routinely used technique, such as per ERCP intraductal biopsies, which had a sensitivity of $48.1 \%$ in a recent meta-analysis [11]. Also, several studies report on methods attempting to improve diagnostic yield from endobiliary samples through researching new biological markers. For example, fluorescent in situ hybridization seems to have very high diagnostic performances ( $\mathrm{Se}=89 \%$ and $\mathrm{Sp}=97 \%$ ) when detection of deletion 9q21 and polysomy is associated with cytologic analysis of brushing [17]. These diagnostic performances could even be better in association with our new method. Also, some new markers are assessed in bile such as neutrophil gelatinase-associated lipocalin (NGAL) with promising results in the diagnosis of malignant stenosis, which suggested that bile is very interesting to study [18]. On the other hand, new endoscopic techniques such as cholangioscopy biopsies and confocal laser endomicroscopy are being developed. The first one suffers from a low sensitivity, around 75\% [19]. The second one requires a really high level of expertise, and despite its excellent sensitivity, its diagnostic performance is still low as its specificity is $67 \%$ in a recent prospective study [20]. For now, none of these techniques seem to have a greater diagnostic accuracy and they are costly procedures which are not easily accessible to the majority of endoscopic centers.

In conclusion, our study shows that performing bile aspiration before and after brushing during ERCP significantly increased the ability to diagnose malignant bile-duct strictures. This method could be used as a standard procedure to improve the diagnosis of malignant strictures, especially cholangiocarcinoma.

\section{Competing interests: None}

\section{Institutions}

${ }^{1}$ Clinique Universitaire d'Hépato-gastroentérologie, Pôle Digidune, CHU Grenoble, Alpes

2 INSERM U1209, Grenoble, France

${ }^{3}$ Faculté de Médecine, Université Grenoble Alpes, Grenoble, France

${ }^{4}$ Clinique Universitaire de Cytologie et Pathologie, Pôle Biologie et Pathologie, CHU Grenoble, Alpes

${ }^{5}$ Pôle Recherche, CHU Grenoble, Alpes

${ }^{6}$ Centre de Recherche en Nutrition Humaine Rhône-Alpes, Lyon, France

${ }^{7}$ Inserm U1055-Bioénergétique, Université Grenoble Alpes, France

${ }^{8}$ Clinique Universitaire de chirurgie digestive, Pôle Digidune, CHU Grenoble, Alpes

${ }^{9}$ Clinique Universitaire de Radiologie et Imagerie Médicale, Pôle Imagerie, CHU Grenoble, Alpes

\section{References}

1 Khan SA, Thomas HC, Davidson BR et al. Cholangiocarcinoma. Lancet 2005; 366: $1303-1314$

2 Razumilava N, Gores GJ. Cholangiocarcinoma. Lancet 2014; 383: $2168-2179$

3 Mosconi S, Beretta GD, Labianca R et al. Cholangiocarcinoma. Crit Rev Oncol Hematol 2009; 69: 259-270

4 Varghese JC, Farrell MA, Courtney G et al. A prospective comparison of magnetic resonance cholangiopancreatography with endoscopic retrograde cholangiopancreatography in the evaluation of patients with suspected biliary tract disease. Clin Rad 1999; 54: 513-520

$5 \mathrm{Kim} \mathrm{MJ}$, Mitchell DG, Ito K et al. Biliary dilatation: differentiation of benign from malignant causes-value of adding conventional MR imaging to MR cholangiopancreatography. Radiology 2000; 214: 173-181

6 Osnes M, Serck-Hanssen A, Myren J. Endoscopic retrograde brush cytology (ERBC) of the biliary and pancreatic ducts. Scand J Gastroenterol 1975; 10: 829-831

7 Vandervoort J, Soetikno RM, Tham TC et al. Risk factors for complications after performance of ERCP. Gastrointest Endosc 2002; 56: 652 656

8 Cotton PB, Garrow DA, Gallagher J et al. Risk factors for complications after ERCP: a multivariate analysis of 11,497 procedures over 12 years. Gastrointest Endosc 2009; 70: 80-88

9 Trikudanathan G, Navaneethan $U$, Njei B et al. Diagnostic yield of bile duct brushings for cholangiocarcinoma in primary sclerosing cholangitis: a systematic review and meta-analysis. Gastrointest Endosc 2014; 79: 783-789

10 Burnett AS, Calvert TJ, Chokshi RJ. Sensitivity of endoscopic retrograde cholangiopancreatography standard cytology: 10-y review of the literature. J Surg Res 2013; 184: 304-311

11 Navaneethan $U$, Njei B, Lourdusamy $V$ et al. Comparative effectiveness of biliary brush cytology and intraductal biopsy for detection of malignant biliary strictures: a systematic review and meta-analysis. Gastrointest Endosc 2015; 81: 168 - 176

12 Fogel EL, deBellis M, McHenry L et al. Effectiveness of a new long cytology brush in the evaluation of malignant biliary obstruction: a prospective study. Gastrointest Endosc 2006; 63: 71 - 77

13 Shieh FK, Luong-Player A, Khara HS et al. Improved endoscopic retrograde cholangiopancreatography brush increases diagnostic yield of malignant biliary strictures. World J Gastrointest Endosc 2014; 6: $312-317$

14 Curcio G, Traina M, Mocciaro F et al. Intraductal aspiration: a promising new tissue-sampling technique for the diagnosis of suspected malignant biliary strictures. Gastrointest Endosc 2012; 75: 798 - 804

15 Masci E, Toti G, Mariani A et al. Complications of diagnostic and therapeutic ERCP: a prospective multicenter study. Am J Gastroenterol 2001; 96: 417-423

16 Adamsen $S$, Olsen $M$, Jendresen $M B$ et al. Endobiliary brush biopsy: Intra- and interobserver variation in cytological evaluation of brushings from bile duct strictures. Scand J Gastroenterol 2006; 41: 597-603

17 Gonda TA, Glick MP, Sethi A et al. Polysomy and p16 deletion by fluorescence in situ hybridization in the diagnosis of indeterminate biliary strictures. Gastrointest Endosc 2012; 75: 74-79

18 Zabron AA, Horneffer-van der Sluis VM, Wadsworth CA et al. Elevated levels of neutrophil gelatinase-associated lipocalin in bile from patients with malignant pancreatobiliary disease. Am J Gastroenterol 2011; 106: 1711-1717

19 Meining A, Chen YK, Pleskow D et al. Direct visualization of indeterminate pancreaticobiliary strictures with probe-based confocal laser endomicroscopy: a multicenter experience. Gastrointest Endosc 2011; 74: $961-968$

20 Navaneethan $U$, Hasan MK, Lourdusamy Vet al. Single-operator cholangioscopy and targeted biopsies in the diagnosis of indeterminate biliary strictures: a systematic review. Gastrointest Endosc 2015; 81: $168-176$ 